\title{
CRITERION EQUATIONS OF HEAT TRANSFER FOR ,N“ HORIZONTAL PIPES ONE ABOVE ANOTHER AT NATURAL CONVECTION IN LINEAR METHOD OF APPROXIMATION
}

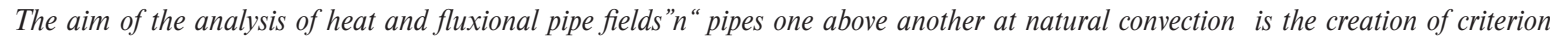
equation on the basis of which the heat output of heat transfer from pipe oriented areas one above another with given spacing could be quantified. For creating criteria-relation and calculating the Nusselt number for " $n$ " tubes one above the other were used computational data from Ansys-Fluent software and criterion equations for a single tube. Based on the heat transfer analysis of a single horizontal tube will be used criterial equation for calculating the Nusselt number according to Morgan. For themselves derive criteria equations data evaluated were calculated and adjusted for mathematical processing of results. Formation criterion equations was based on approximation of planar curves prepared from adjusted modeled data by using CFD. In calculating was used the least squares approximation method.

Keywords: Convection, heat transfer, thermal temperature, criterial equation, natural convection.

\section{Introduction}

On the basis of this comparison where equalities were gained [1 and 2] in calculated and modelled results, models were created in the programme Ansys-Fluent for"n" horizontal pipes one above another.

Data from this program and famous criterion equation for one pipe were used to create criterion relation to calculate Nusselt number [3 and 4] for" $n$ " pipes one above another. A criterion relation for calculating Nusselt number according to Morgan [5 and 6] will be used on the basis of analyses of heat transfer of one horizontal pipe.

To deduce criterion relation, calculated data were evaluated and modified for mathematical processing of results. The creation of criterion equation came out from the approximation of a space curve formed from modified modelled data with the help of CFD. The least squares fitting method was used. A linear model of criterion equation for " $n$ " pipes one above another was created.

\section{Simulations}

The aim of analysis of temperature and stream fields of"n" pipes one above another at natural convection is to create a criterion equation on the basis of which a heat output of heat transfer from pipe oriented areas above each other with given spacing could be quantified. At present a sum of criterion equations exists for simple geometrical shapes of individual oriented geometrical areas but the criterion equation which would consider interaction of fluxional field generated by free convection from multiple oriented areas is not mentioned in standardly accessible technical literature and other magazine publications. Creation of criterion equation for calculation of heat output is significant for quantification of heat outputs calculations of geometrically more complicated heat transfer areas in engineering practice and, furthermore, for optimization of processes such as schemes of pipe heat bodies and many other applications in technical practice that are related to heat transfer by free convection [7, 8 and 9].

The process of finding a new criterion equation for above mentioned geometries was carried out on the basis of numerical experiment by simulation of heat transfer for various thermokinetic and geometrical parameters of pipe alignment one above another. Some simulations were verified by measuring the output of real pipe system in a specialized thermostatic chamber. Used numeric model of CFD method was validated in this way.

Simulations of ten pipes one above another with the diameter of $27 \mathrm{~mm}$ at a wall temperature $30^{\circ} \mathrm{C}, 45^{\circ} \mathrm{C}, 60^{\circ} \mathrm{C}, 75^{\circ} \mathrm{C}, 90^{\circ} \mathrm{C}$, $105^{\circ} \mathrm{C}$ and at a surrounding temperature $20^{\circ} \mathrm{C}$ were carried out in order to put together criterion relation for" $n$ " pipes one above another at natural convection on the basis of calculations in the programme Ansys - Fluent, Fig. 1. Heat output of pipe

\footnotetext{
* ${ }^{1}$ Andrej Kapjor, ${ }^{1}$ Jozef Huzvar, ${ }^{2}$ Branislav Ftorek, ${ }^{1}$ Martin Vantuch

${ }^{1}$ Department of Power Engineering, Faculty of Mechanical Engineering, University of Zilina, Slovakia

${ }^{2}$ Department of Applied Mathematics, Faculty of Mechanical Engineering, University of Zilina, Slovakia

E-mail: andrej.kapjor@fstroj.uniza.sk
} 
system with this diameter was measured also in the thermostatic chamber.

The modelling of heat transport from ten horizontal pipes in the programme Ansys 13 - Workbench was carried out in the analysis system Fluid Flow (Fluent) [10].

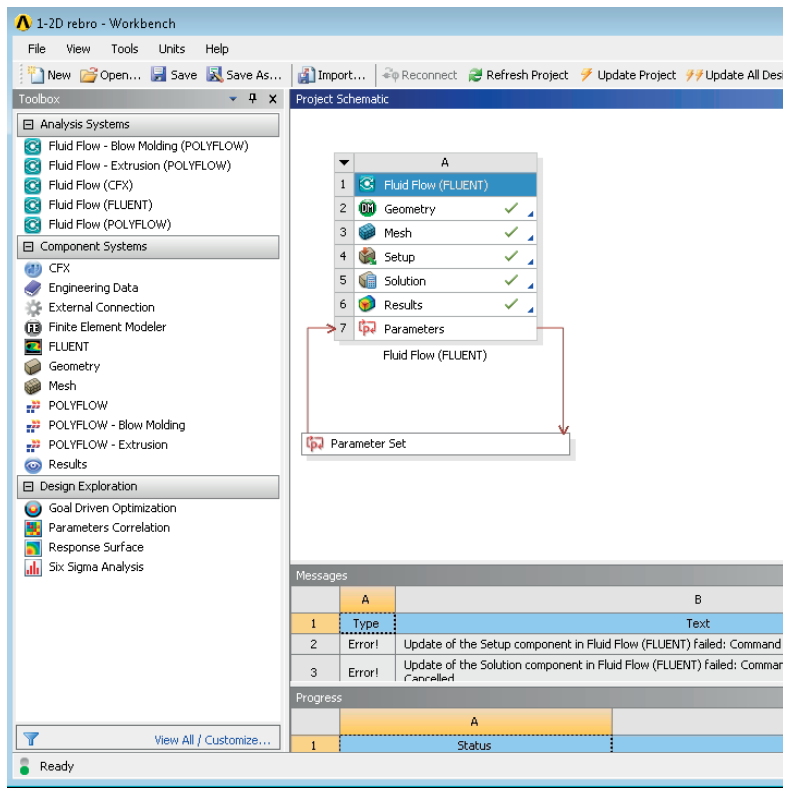

Fig. 1 The basic scheme of calculation

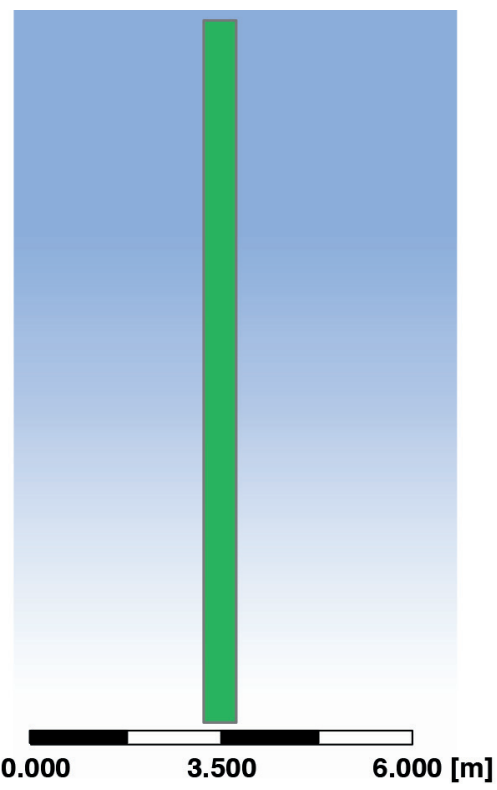

Fig. 2 The geometry of ten pipes one above another and its surrounding

Figure 1 shows a basic scheme of the way of analyzing the heat transfer by natural convection from ten horizontal pipes in the air. Primarily, it would be necessary to create a geometry of ten horizontal pipes together with the surrounding of pipes (a model of placing system of pipes into nondimensional space) to visualize temperature fields as well as to calculate output characteristics. To simplify calculations and due to the geometry of pipes, a 2-D model of heat transport calculation from horizontal pipe with given parameter for spacing of ten horizontal pipes could be used Fig. 2.

In the next step a computing grid with higher density around pipes was created in the subsystem of the programme Ansys in order to receive better accuracy of calculations of output characteristics of natural convection of horizontal pipes - Fig. 2. After the creation computing mesh with higher density of meshing around the tubes [Fig. 3] the model was imported into computing module Fluent where 2-D calculation model was chosen [11 and 12].

Similar boundary conditions for calculation were entered in the programme Fluent:

- unsteady model (because of instability of streaming),

- laminar model of streaming (results from the calculation of Rayleigh number of similarity theory where the critical value for laminar streaming is $\mathrm{Ra}_{\text {krit }}=10^{9}$ ),

- temperature of pipe's walls - given as parameter,

- limiting control area for natural convection analysis was entered as "pressure outlet" with given temperature of $20^{\circ} \mathrm{C}$, which means $\mathrm{T}^{\infty}=20^{\circ} \mathrm{C}$,

- gravity acceleration $9.81 \mathrm{~m} \cdot \mathrm{s}^{-2}$,

- Boussinesq model for calculation of air density, which is useful for natural convection (according to the Fluent publication),

- under-relaxation factors except for energy and pressure, they decreased by half (according to the Fluent publication).

A nonstationary model was selected (unsteady model) which is suitable for calculation of a free convection from more complicated shapes of heat exchange areas [13 and 14].

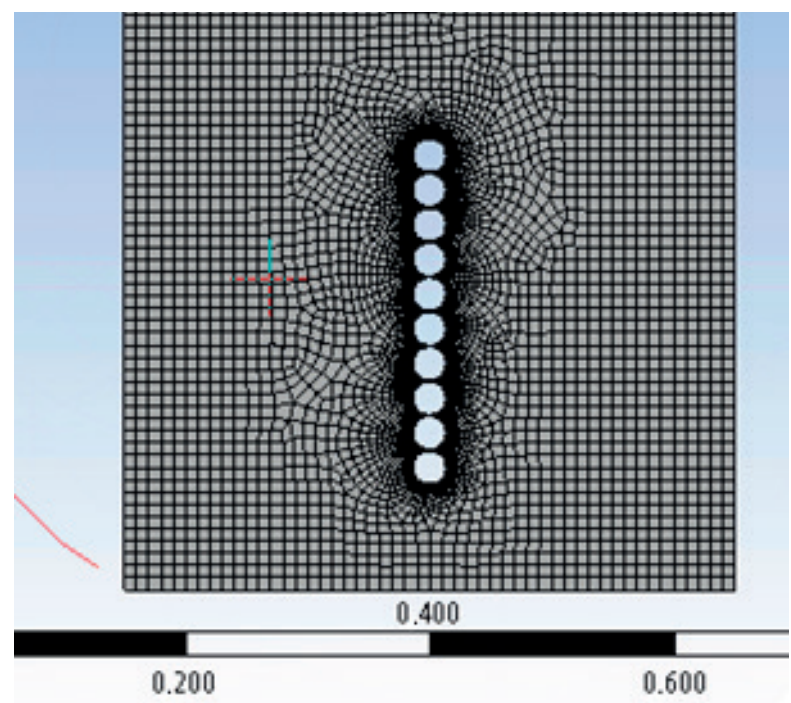

Fig. 3 Computing grid vertical plate and its surrounding 


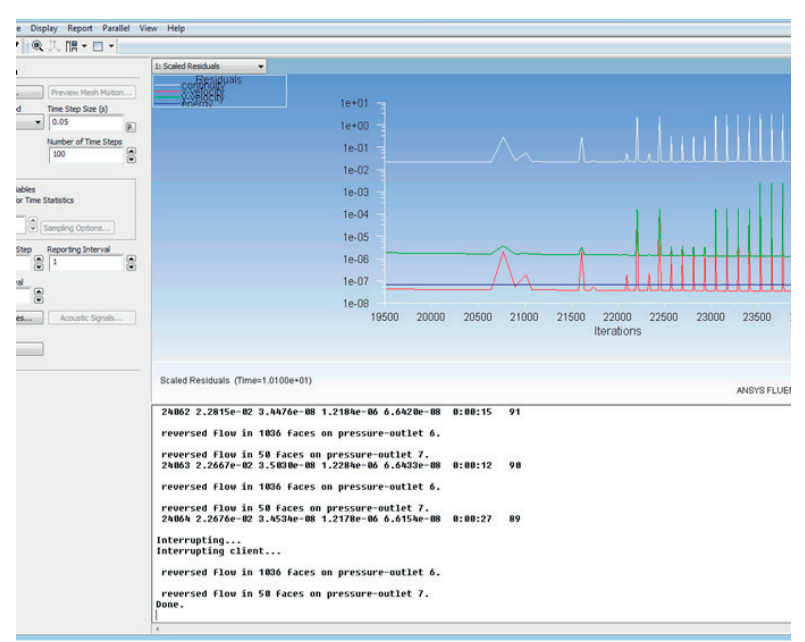

Fig. 4 Process of computing in programme Ansys-Fluent

\section{Criterion relation}

Calculation of heat output (Fig. 4) was carried out after entering boundary conditions and after configuration of parameters for parametric analysis where eighteen spacings" $S$ “ in vertical direction were stated. When pipe's wall temperature was entered in the programme Fluent as another parameter, automatically another column was generated in which it was possible to change temperature values. When selecting the "Updatealldesign point", the programme automatically recounts all the entered calculation values and writes defined outgoing parameters from the Fluent code into another column. In this case a heat output was used as outgoing parameter. Such analyses were carried out for more temperatures, namely, for wall temperatures $30^{\circ} \mathrm{C}, 45^{\circ} \mathrm{C}, 60^{\circ} \mathrm{C}, 75^{\circ} \mathrm{C}, 90^{\circ} \mathrm{C}$ and $105^{\circ} \mathrm{C}$. Heat outputs of ten horizontal pipes at these temperatures are shown in Table 1 and in graph 1 where except for spacing a new parameter for calculating the output S/D was given. The pictures show reciprocal interaction of individual pipes where at minimum spacing (for the dimensionless parameter $S / D=1$ ) the pack of pipes behaved similary to a vertical panel After following increase of S/D the interaction was expressed not only at increasing heat output Fig. 5, but also at creating temperature fields and at stream character. As also seen in these pictures Figs. 6 - 11 the streaming process at lower parameters S/D is relatively stable, stationary, where a fine waving occurs only at the end of the reach of the air [15].
Heat outputs of ten horizontal pipes at a surrounding temperature $20^{\circ} \mathrm{C}$ and pipe 's wall temperatures $30-105^{\circ} \mathrm{C}$

Table 1

\begin{tabular}{|c|c|c|c|c|c|c|}
\hline $\mathrm{S} / \mathrm{D}$ & $\begin{array}{c}30^{\circ} \mathrm{C} \\
\mathrm{Q}[\mathrm{W}]\end{array}$ & $\begin{array}{c}45^{\circ} \mathrm{C} \\
\mathrm{Q}[\mathrm{W}]\end{array}$ & $\begin{array}{c}60^{\circ} \mathrm{C} \\
\mathrm{Q}[\mathrm{W}]\end{array}$ & $\begin{array}{c}75^{\circ} \mathrm{C} \\
\mathrm{Q}[\mathrm{W}]\end{array}$ & $\begin{array}{c}90^{\circ} \mathrm{C} \\
\mathrm{Q}[\mathrm{W}]\end{array}$ & $\begin{array}{c}105^{\circ} \mathrm{C} \\
\mathrm{Q}[\mathrm{W}]\end{array}$ \\
\hline 1.05 & 24.85 & 82.89 & 154.57 & 236.19 & 325.90 & 422.60 \\
\hline 1.4 & 31.10 & 104.23 & 195.98 & 301.18 & 417.07 & 542.27 \\
\hline 1.5 & 32.77 & 109.62 & 205.81 & 316.77 & 439.31 & 572.34 \\
\hline 1.75 & 36.16 & 121.58 & 227.12 & 350.48 & 485.04 & 630.22 \\
\hline 2 & 39.28 & 133.23 & 248.62 & 382.10 & 527.49 & 684.03 \\
\hline 2.5 & 45.85 & 159.93 & 293.44 & 457.82 & 621.90 & 805.44 \\
\hline 3 & 51.24 & 176.65 & 350.63 & 518.94 & 727.33 & 937.22 \\
\hline 3.5 & 54.87 & 192.42 & 363.47 & 561.12 & 764.37 & 974.49 \\
\hline 4 & 58.95 & 210.29 & 403.87 & 618.16 & 848.46 & 1089.57 \\
\hline 4.5 & 58.81 & 202.40 & 384.76 & 585.91 & 795.60 & 1015.09 \\
\hline 5 & 63.77 & 224.60 & 432.04 & 655.66 & 900.33 & 1165.18 \\
\hline 7.5 & 62.18 & 231.60 & 449.60 & 671.39 & 923.33 & 1192.95 \\
\hline 10 & 58.46 & 240.45 & 464.92 & 716.46 & 983.14 & 1284.73 \\
\hline 15 & 52.40 & 212.25 & 464.09 & 727.93 & 1025.62 & 1361.48 \\
\hline 20 & 51.25 & 16.91 & 397.70 & 715.66 & 1010.09 & 1306.05 \\
\hline 25 & 50.17 & 158.99 & 299.56 & 562.64 & 932.84 & 1281.74 \\
\hline 30 & 50.11 & 158.30 & 287.23 & 434.69 & 625.30 & 839.26 \\
\hline 35 & 50.05 & 158.28 & 287.22 & 434.50 & 600.12 & 838.00 \\
\hline
\end{tabular}

By further increase of S/D the heat transfer at natural convection intensifies by reciprocal influencing of individual pipes. Furthermore, streaming gets nonstationary on upper pipes that are the most influenced ones. By further increase of S/D the reciprocal interaction of pipes is being decreased which causes decreasing of heat output at natural convection till such S/D ratio is achieved where pipes are not being influenced at all and no other change of heat output at natural convection occurs. As evident from these analyses and from Fig. 5, it is possible to divide the process of heat transport at natural convection from" $n$ " pipes in four output areas. The area one is characterized by huge increase of heat output at natural convection.

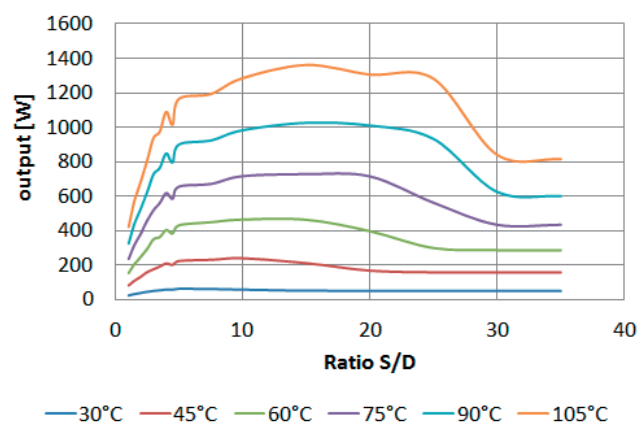

Fig. 5 Heat outputs of ten horizontal pipes at a surrounding temperature $20^{\circ} \mathrm{C}$ and pipe's wall temperatures $30-105^{\circ} \mathrm{C}$ 


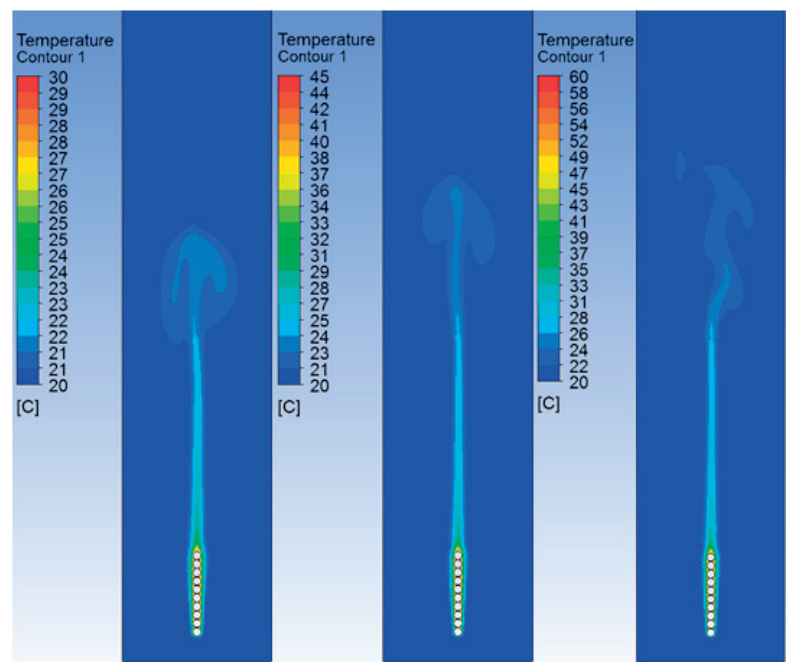

Fig. 6 Temperature fields of ten horizontal pipes with the diameter $27 \mathrm{~mm}$, with given ratio $S / D 1.05$ and surrounding temperature $20^{\circ} \mathrm{C}$

An insignificant increase is present in area two. In area three decreasing of heat output occurs because of the influence of interaction decrease. Area four is characterized by constant heat output which means that individual pipes are not being influenced. The pipe's wall temperature and the surrounding temperature have a very big influence on a clear definition of borders of these four areas which will be defined by non-dimensional temperature $T \infty /$ Ts when searching for a suitable criterion relation.

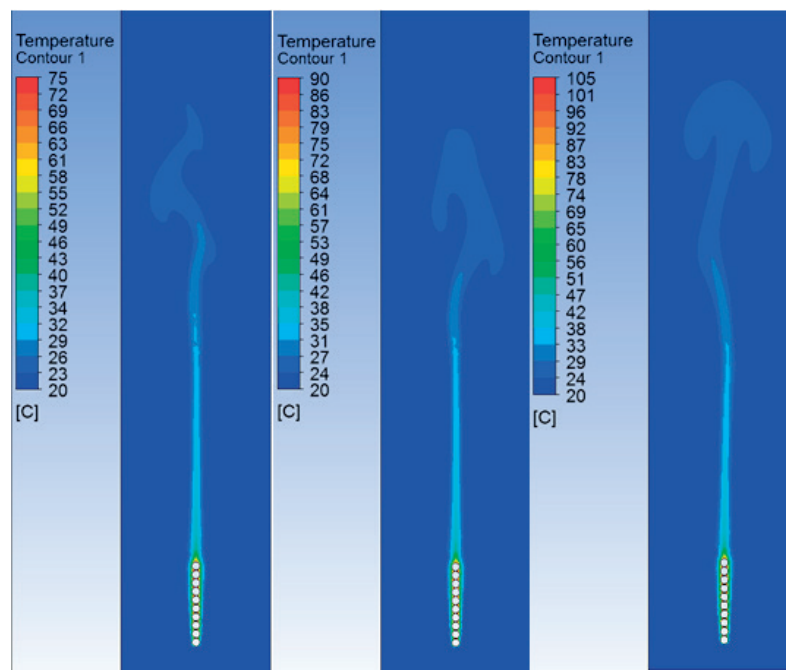

Fig. 7 Temperature fields of ten horizontal pipes with the diameter $27 \mathrm{~mm}$, with given ratio $S / D 1.05$ and surrounding temperature $20^{\circ} \mathrm{C}$

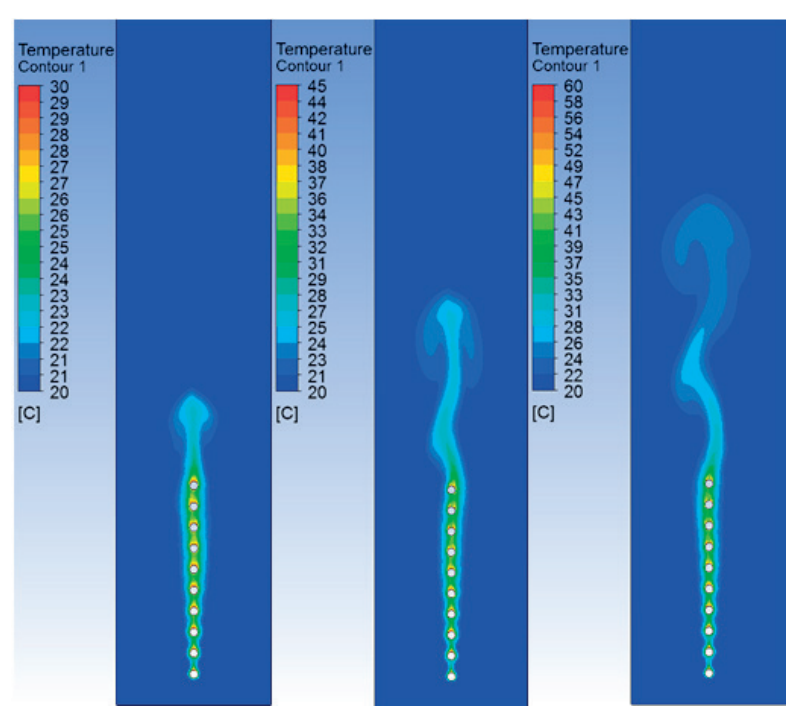

Fig. 8 Temperature fields of ten horizontal pipes with the diameter $27 \mathrm{~mm}$, with given ratio $S / D 2.5$ and surrounding temperature $20^{\circ} \mathrm{C}$

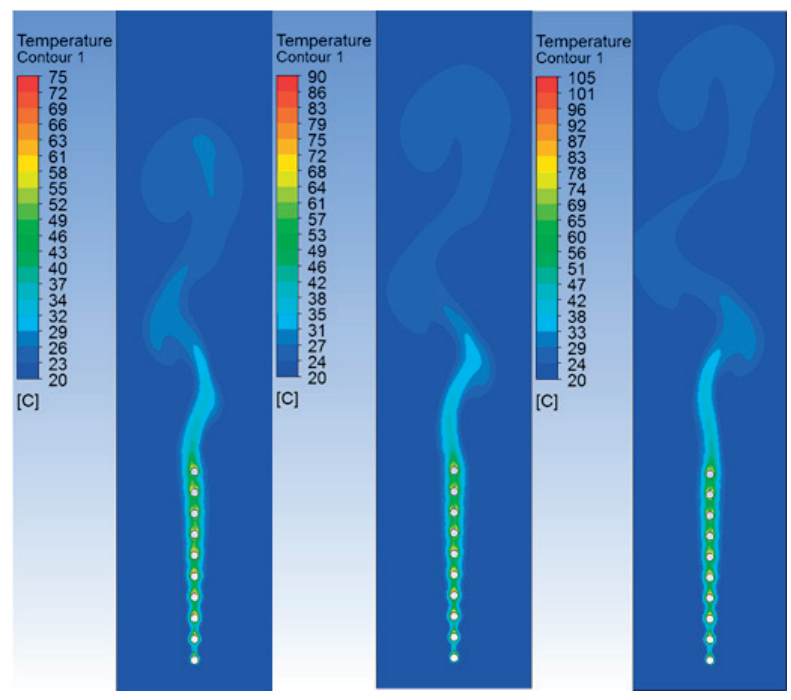

Fig. 9 Temperature fields of ten horizontal pipes with the diameter $27 \mathrm{~mm}$, with given ratio $S / D 2.5$ and surrounding temperature $20^{\circ} \mathrm{C}$ 


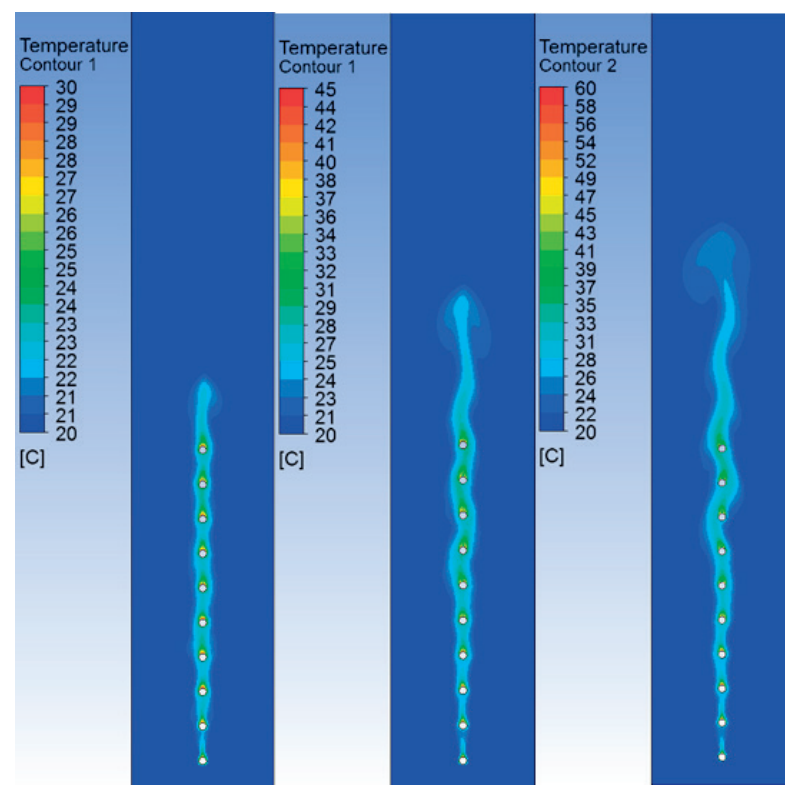

Fig. 10 Temperature fields of ten horizontal pipes with the diameter $27 \mathrm{~mm}$, with given ratio $S / D 4.5$ and surrounding temperature $20^{\circ} \mathrm{C}$

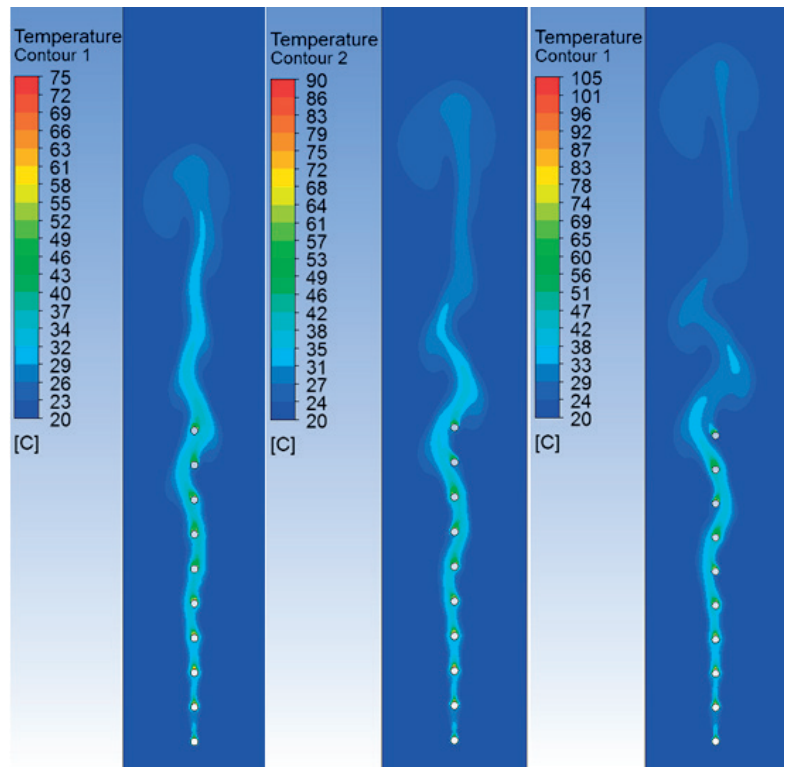

Fig. 11 Temperature fields of ten horizontal pipes with the diameter $27 \mathrm{~mm}$, with given ratio $S / D 4.5$ and surrounding temperature $20^{\circ} \mathrm{C}$

A criterion relation for calculating Nusselt number according to Morgan will be used on the basis of heat transfer analyses of one horizontal pipe:

$\overline{N u_{d}}=\frac{\bar{\propto} d}{\lambda}=C R a_{d}^{n}[1]$
Multiple article $\mathrm{C}$ and exponent $\mathrm{n}$

Table 2

\begin{tabular}{|l|l|l|}
\hline $\mathrm{Ra}_{\mathrm{d}}$ & $\mathrm{C}$ & $\mathrm{n}$ \\
\hline $10^{-10}-10^{-2}$ & 0.675 & 0.058 \\
\hline $10^{-2}-10^{2}$ & 1.02 & 0.148 \\
\hline $10^{2}-10^{4}$ & 0.85 & 0.188 \\
\hline $10^{4}-10^{7}$ & 0.48 & 0.25 \\
\hline $10^{7}-10^{12}$ & 0.125 & 0.333 \\
\hline
\end{tabular}

Table 2 shows $\mathrm{C}$ and $\mathrm{n}$ exponent in Ra changes. It is necessary to evaluate calculated data or to modify them for mathematical processing of results to be able to deduce criterion relation. More variants for creation of given equation were analysed while analysing and processing data in order to put together criterion equation. As mentioned above the heat output at natural convection from" $n$ " horizontal pipes depends on ratio S/D (nondimensional spacing) as well as on To/Ts. This implies that the searched functional dependency will have a shape of functional dependency of space area. Fig. 12 shows functional dependencies of Nusselt number of pipe bundle which was calculated from general relation for calculating $\mathrm{Nu}$ number

$\overline{N u_{D z v}}=\frac{\alpha L}{\lambda}[1]$

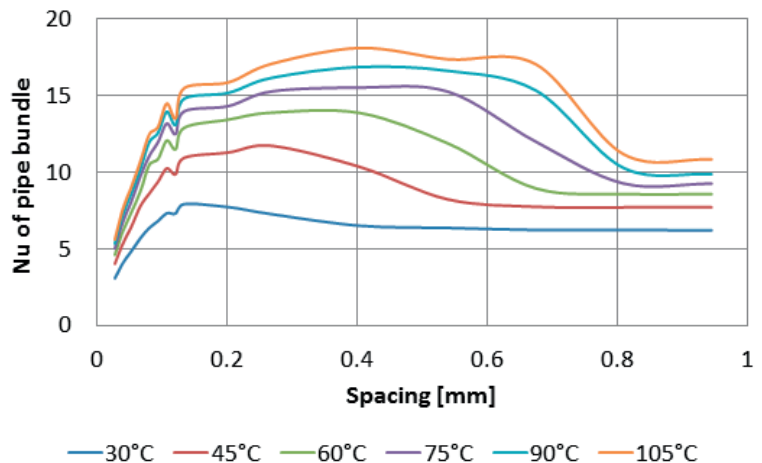

Fig. 12 Process of ratio Nu depending on spacing, pipe's wall temperature $30^{\circ} \mathrm{C}-105^{\circ} \mathrm{C}$ and surrounding temperature $20^{\circ} \mathrm{C}$

As it is necessary to find the dependency of Nusselt number of " $n$ " horizontal pipes one above another $\left(\mathrm{Nu}_{\mathrm{DzV}}=\mathrm{Nu}_{\mathrm{d}}{ }^{*} \mathrm{f}(\mathrm{S} /\right.$ $\left.\mathrm{D},\left(\infty / \mathrm{T}_{\mathrm{s}}\right)\right)$ the data were calculated and Fig. 13 was created. As seen in the graph it would be very difficult to create a functional dependency for such an area and created functional dependency would show a significant mistake. For that reason it was necessary to bring some physical dependency into this problem. By dividing of $\mathrm{Nu}_{\mathrm{Dzv}}$ by conjunction of $\mathrm{Nu}_{\mathrm{d}}(\mathrm{Nu}$ of one pipe), using parameter S/D and parameter $T \infty / T_{s}$ we got data from which Fig. 14 and 3-D graph of space area were created. It is evident from these graphs that the functional dependency has an exponential character. On 
the basis of these analyses the final criterion equation will be as follows:

$$
\overline{N u_{D z v}}=N u_{d} \cdot \frac{S}{D} \cdot \frac{T_{\infty}}{T_{S}} \cdot f\left(\frac{S}{D} \cdot \frac{T_{\infty}}{T_{S}}\right)
$$

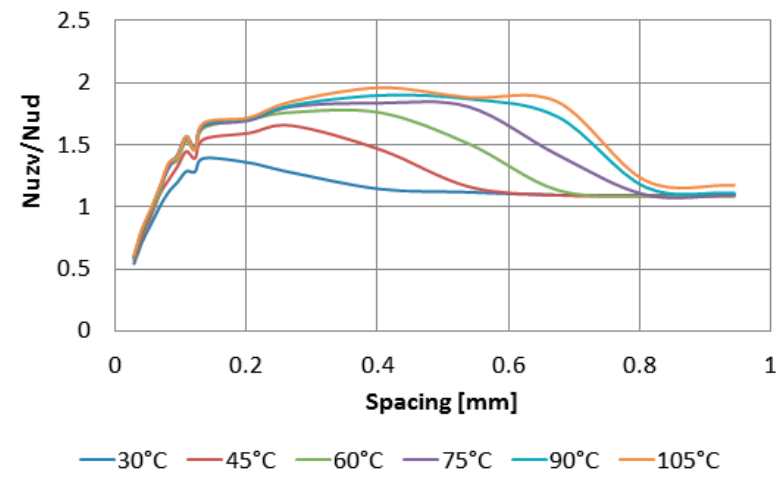

Fig. 13 Process of ratio Nuzv/Nud depending on spacing, pipe's wall temperature $30^{\circ} \mathrm{C}-105^{\circ} \mathrm{C}$ and surrounding temperature $20^{\circ} \mathrm{C}$

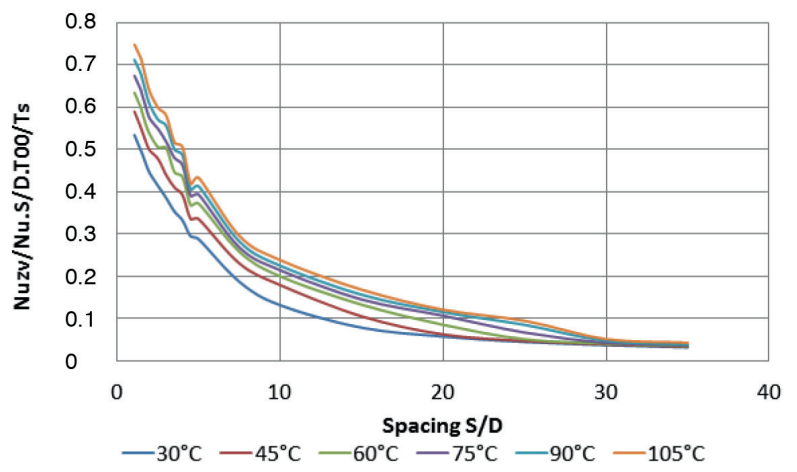

Fig. 14 Process of ratio Nuzv/(Nud.S/D.To/Ts) depending on $S / D$, pipe's wall temperature $30^{\circ} \mathrm{C}-105^{\circ} \mathrm{C}$ and surrounding temperature $20^{\circ} \mathrm{C}$

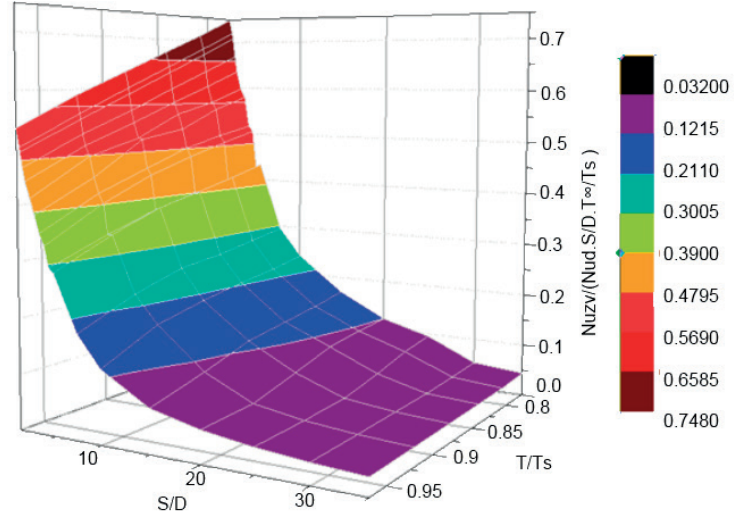

Fig. 15 Process of ratio $N u_{z} /\left(N u_{d} S / D . T_{\alpha} / T_{s}\right)$ depending on $S / D$ a $T_{\alpha} / T_{s}$
Creation of criterion equation comes out from previous analysis of data and their following processing which results in the conclusion that the final criterion equation will be as follows

$\overline{N u_{D z v}}=N u_{d} \cdot \frac{S}{D} \cdot \frac{T_{\infty}}{T_{S}} \cdot f\left(\frac{S}{D} \cdot \frac{T_{\infty}}{T_{S}}\right)$

We demand that the final curve or area is continuous and as well as possible approximated points of empiric polygon which is given by calculated data. This approximation is necessary for defining the process of an event for any argument value and it is used for quantification of physical-technical relations. While creating criterion equation at approximation, we will use the least squares method for the function of two variables

$f\left(\frac{S}{D}, \frac{T_{\infty}}{T_{S}}\right)$

To create functional dependency it is necessary to choose approximate basis functions which highly influence the correctness of results. For the function of two variables in general a higher number of elements is necessary than for the function of one variable. As the result of these facts we see big equation systems at approximation of the function with two variables and the question of solution stability regarding round-off errors can be brought to the forefront. For the approximation of the area as seen in Fig. 15, we used three methods namely a linear model, non-linear model and interpolation approach - using cubic splines.

Linear model:

This model was proved good for the interval $\frac{S}{D}$, which is divided in four parts where we chose for basic functions the conjunction of powers $\left(\frac{T_{\infty}}{T_{S}}\right)^{\alpha} \cdot\left(\frac{S}{D}\right)^{\beta}, \alpha+\beta \leq 3$. This means that the final polynomial of two variables was of a third degree and the number of basic functions was $n=10$. A good compromise was gained between the simplicity of basis functions and the total degree of polynomial. A low degree of polynomial suppresses the inclination of polynomial approximation to parasitic oscillations and this would completely devalue the results. The relative error of this polynomial model to enter data was in given intervals up to $8 \%$ which can be considered as a very good result [16]. Constants of the equation for each interval are shown in Tables 3, 4, 5 and 6.

The approximation equation is as follows

$f\left(\frac{T_{\infty}}{T_{S}}, \frac{S}{D}\right)=c_{1}+c_{2} x+c_{3} y+c_{4} x^{2}+c_{5} x y+$ $+c_{6} y^{2}+c_{7} x^{3}+c_{8} x^{2} y+c_{9} x y^{2}+c_{10} y^{3}$

where we identify

$x=\frac{T_{\infty}}{T_{S}}, y=\frac{S}{D}$ 
Constants of the equation $2 \frac{S}{D} \in<1.05 ; 5>$

\begin{tabular}{|l|l|l|l|l|}
\hline $\mathrm{c} 1$ & $\mathrm{c} 2$ & $\mathrm{c} 3$ & $\mathrm{c} 4$ & $\mathrm{c5}$ \\
\hline 6.4978 & -17.0293 & -0.6537 & 17.8059 & 1.0878 \\
\hline $\mathrm{c6}$ & $\mathrm{c} 7$ & $\mathrm{c} 8$ & $\mathrm{c} 9$ & $\mathrm{c} 10$ \\
\hline 0.0173 & -6.6608 & -0.5758 & 0.0042 & -0.0017 \\
\hline
\end{tabular}

Constants of the equation $2 \frac{S}{D} \in<5 ; 15>$

Table 4

\begin{tabular}{|l|l|l|l|l|}
\hline $\mathrm{c} 1$ & $\mathrm{c} 2$ & $\mathrm{c} 3$ & $\mathrm{c} 4$ & $\mathrm{c} 5$ \\
\hline 8.7138 & -26.6054 & -0.2258 & 31.6232 & 0.0074 \\
\hline $\mathrm{c} 6$ & $\mathrm{c} 7$ & $\mathrm{c} 8$ & $\mathrm{c} 9$ & $\mathrm{c} 10$ \\
\hline 0.0176 & -12.985 & 0.0594 & -0.0043 & -0.0004 \\
\hline
\end{tabular}

Constants of the equation $2 \frac{S}{D} \in<15 ; 25>$

Table 5

\begin{tabular}{|l|l|l|l|l|}
\hline $\mathrm{c} 1$ & $\mathrm{c} 2$ & $\mathrm{c} 3$ & $\mathrm{c} 4$ & $\mathrm{c5}$ \\
\hline 18.8068 & 32.406 & -4.3318 & -32.772 & -0.4562 \\
\hline $\mathrm{c} 6$ & $\mathrm{c} 7$ & $\mathrm{c} 8$ & $\mathrm{c} 9$ & $\mathrm{c} 10$ \\
\hline 0.2303 & 10.4933 & 0.2714 & 0 & -0.0038 \\
\hline
\end{tabular}

Constants of the equation $2 \frac{S}{D} \in<25 ; 35>$

Table 6

\begin{tabular}{|l|l|l|l|l|}
\hline c1 & c2 & c3 & c4 & c5 \\
\hline 24.8859 & -9.2346 & -2.1961 & 1.2677 & 0.4729 \\
\hline c6 & c7 & c8 & c9 & c10 \\
\hline 0.0662 & 1.1953 & -0.1222 & 0.004 & -0.0007 \\
\hline
\end{tabular}

Relevant calculations of this linear polynomial model are carried out in the Matlab.
The final criterion equation for Nusselt number of " $n$ " pipes one above another will be as follows:

$\overline{N u_{D z v}}=N u_{d} \cdot \frac{S}{D} \cdot \frac{T_{\infty}}{T_{S}} \cdot\left(c_{1}+c_{2} x+c_{3} y++c_{4} x^{2}\right.$
$\left.+c_{5} x y+c_{6} y^{2}+c_{7} x^{3}+c_{8} x^{2} y++c_{9} x y^{2}+c_{10} y^{3}\right)$

Where $\mathrm{x}$ is $\frac{T_{\infty}}{T_{S}}$ and $\mathrm{y}$ is $\frac{S}{D}$.

\section{Conclusion}

The article deals with the topic of heat transfer from oriented heat exchange areas in relation to creating a criterion equation for " $n$ " horizontal pipes one above another. On the basis of this comparison where equalities were gained in calculated and modelled results, models were created in the programme AnsysFluent for " $n$ " horizontal pipes one above another.

As mentioned above the heat output at natural convection from " $n$ " horizontal pipes depends on ratio S/D (non-dimensional spacing) as well as on To/Ts. In creating the criterion equation was used in approximation the least squares method. To create functional dependency it was necessary to choose suitable basic functions which highly influence the correctness of results.

In the near future we want to simplify these equations and check their functionality in all extensity. For this verification we proposed a new measurement and evaluation state in a thermostatic chamber where will be every pipe made from electric spiral. These spirals will be separately connected to a DC source of electrical power.

\section{Acknowledgement}

The research is supported by the European Regional Development Fund and the Slovak state budget for the project “Research Centre of University of Zilina”, ITMS 26220220183.

\section{References}

[1] INCROPERA, F. P., DEWITT, D. P, BERGMAN, T. L., LAVINE, A.: Fundamentals of Heat and Mass Transfer. $6^{\text {th }}$ ed. John Wiley, New York, 2007.

[2] MORAN, M. J., SHAPIRO, H. N., MUNSON, B. R., DEWITT, D. P.: Introduction of Thermal Systems Engineering: Thermodynamics, Fluid Mechanics and Heat Transfer. John Wiley\&Sons, Inc, 2003, ISBN 0-471-20490-0.

[3] PILAT, P., PATSCH, M., MALCHO, M.: Solar Heat Utilization for Adsorption Cooling Device. Conference on Experimental Fluid Mechanics (EFM) Jicin, November, 2011.

[4] JAKUBSKY, M., LENHARD, R., VANTUCH, M., MALCHO, M.: Borehole Model for Simulation Transport Geothermal Heat with Heat Pipe System and with Forced Circulation of Heat Carrier. Conference on Experimental Fluid Mechanics, EFM 2011, Jicin.

[5] LENHARD, R., JAKUBSKY, M., MALCHO M., JANDACKA, J.: Analysis of Transmission Phenomena in Low-potential Heat Transport by Heat Pipes in the Deep-borehole Simulator. Communications - Scientific Letters of the University of Zilina, vol. 14, No. 3, 2012, 10-16.

[6] BRESTOVIC, T., JASMINSKA, N.: Software Support Development for Numerical Solution of ANSYS CFX. Acta Mechanica et Automatica, vol. 17, No. 4, 2013, 215-221. ISSN 1898-4088. 
[7] CARnOGuRSKA, M., PRIHODA, M., BRESTOVIC, T.: Modelling of Nitrogen Oxides Formation Applying Dimensional Analysis. Chemical and Process Engineering - Inzynieria Chemiczna i Procesowa, vol. 32, No. 3, September 2011. ISSN: 02086425.

[8] DURCANSKY, P., LENHARD, R., JANDACKA, J.: Heat Exchanger Design for Hot Air Ericsson-Brayton Piston Engine. AIP Conference Proc. of $11^{\text {th }}$ Intern. Conference of Numerical Analysis and Applied Mathematics, ICNAAM 2013, Rhodes, 2013.

[9] JANDACKA, J., HOLUBCIK, M., PAPUCIK, S., NOSEK, R.: Combustion of Pellets from Wheat Straw. Acta Montanistica Slovaca, vol. 17, No. 4, 2012, 283-289.

[10] JANDACKA, J., PAPUCIK, S., DEKYS, V., MELICHER, R.: An Analysis of Air Flow at Various Spacing of Fans on a Physical Model of a Road Tunnel, Communications - Scientific Letters of the University of Zilina, vol. 10, No. 3, 2008, 40-44.

[11] PRIHODA, J., ZUBIK, P., SULC, J., SEDLAR, M.: Experimental and Numerical Modelling of Turbulent Flow Over an Inclined Backward-facing Step in an Open Channel, Communications - Scientific Letters of the University of Zilina, No. 4A, 2012.

[12] CARNOGURSKA, M., PRIHODA, M., BRESTOVIC, T.: Modelling of Nitrogen Oxiges Formation Applying Dimensional Analysis. Chemical and Process Engineering - Inzynieria Chemiczna i Procesowa, vol. 32, No. 3, September 2011. ISSN: 02086425.

[13] NEMEC, P., CAJA, A., MALCHO, M.: Mathematical Model for Heat Transfer Limitations of Heat Pipe. Mathematical and Computer Modelling, vol. 57, No. 1-2, January 2013, 126-136

[14] LENHARD, R., GAVLAS, S., MALCHO, M.: Numerical Simulation of Borehole Model which Utilizes Low-potential Geothermal Heat. EPJ Web of Conferences. Conference on Experimental Fluid Mechanics, EFM 2011, Jicin, November 2011.

[15] SAGA, M., KOPAS, P., VASKO, M.: Some Computational Aspects of Vehicle Shell Frames Optimization Subjected to Fatigue Life. Communications - Scientific Letters of the University of Zilina, vol. 12, No. 4, 2010, 73-79.

[16] JANDACKA, J., PAPUCIK, S., DEKYS, V., MELICHER, R.: An Analysis of Air Flow at Various Spacing of Fans on a Physical Model of a Road Tunnel, Communications - Scientific Letters of the University of Zilina, vol. 10, No. 3, 2008, $40-44$ 